\title{
Article
}

\section{Intelligent Multi-Agent System for Building Heat Distribution Control with Combined Gas Boilers and Ground Source Heat Pump}

Mokhtar, Maizura, Stables, Matthew, Liu, Xiongwei and Howe, Joe Available at http://clok.uclan.ac.uk/7827/

Mokhtar, Maizura ORCID: 0000-0003-0460-3696, Stables, Matthew ORCID: 0000-0002-9971-9458, Liu, Xiongwei and Howe, Joe (2013) Intelligent MultiAgent System for Building Heat Distribution Control with Combined Gas Boilers and Ground Source Heat Pump. Energy and Buildings, - (-). ---. ISSN 03787788

It is advisable to refer to the publisher's version if you intend to cite from the work. http://dx.doi.org/10.1016/j.enbuild.2013.03.045

For more information about UCLan's research in this area go to http://www.uclan.ac.uk/researchgroups/ and search for <name of research Group>.

For information about Research generally at UCLan please go to http://www.uclan.ac.uk/research/

All outputs in CLoK are protected by Intellectual Property Rights law, including Copyright law. Copyright, IPR and Moral Rights for the works on this site are retained by the individual authors and/or other copyright owners. Terms and conditions for use of this material are defined in the policies page. 


\section{Accepted Manuscript}

Title: Intelligent Multi-Agent System for Building Heat Distribution Control with Combined Gas Boilers and Ground Source Heat Pump

Author: Maizura Mokhtar Matthew Stables Xiongwei Liu Joe Howe

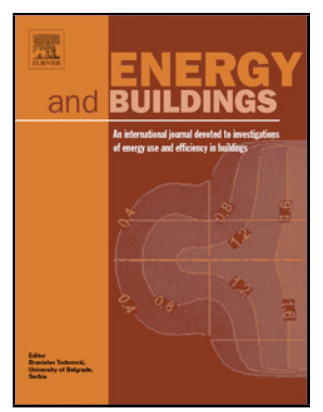

PII:

DOI:

Reference: S0378-7788(13)00213-2 http://dx.doi.org/doi:10.1016/j.enbuild.2013.03.045

To appear in: $\quad E N B$

Received date: $\quad 9-10-2012$

Revised date: $\quad$ 16-3-2013

Accepted date: $\quad$ 23-3-2013

Please cite this article as: Maizura Mokhtar, Matthew Stables, Xiongwei Liu, Joe Howe, Intelligent Multi-Agent System for Building Heat Distribution Control with Combined Gas Boilers and Ground Source Heat Pump, Energy \& Buildings (2013), http://dx.doi.org/10.1016/j.enbuild.2013.03.045

This is a PDF file of an unedited manuscript that has been accepted for publication. As a service to our customers we are providing this early version of the manuscript. The manuscript will undergo copyediting, typesetting, and review of the resulting proof before it is published in its final form. Please note that during the production process errors may be discovered which could affect the content, and all legal disclaimers that apply to the journal pertain. 


\title{
Intelligent Multi-Agent System for Building Heat Distribution Control with Combined Gas Boilers and Ground Source Heat Pump
}

\author{
Maizura Mokhtar ${ }^{\mathrm{a}}$, Matthew Stables ${ }^{\mathrm{a}}$, Xiongwei Liu ${ }^{\mathrm{b}}$, Joe Howe ${ }^{\mathrm{a}}$ \\ ${ }^{a}$ School of Computing, Engineering and Physical Sciences, University of Central Lancashire, \\ Preston, PR1 2HE,UK (email: \{MMokhtar,MStables,JMHowe\}@uclan.ac.uk) \\ ${ }^{b}$ Sustainable Engineering, University of Cumbria,UK (email: Xiongwei.Liu@Cumbria.ac.uk)
}

\begin{abstract}
Intelligent energy system refers to the use of intelligent control strategies with the energy system, which can help minimise energy waste and loss, optimise load control, increase and improve energy efficiency and/or maximise the benefits of renewable energy. Renewable energy and intelligent controls are interlinked and correlated with each other. Without intelligent controls, the full benefits of renewable energy technologies may not be achievable, specifically the Ground Source Heat Pump (GSHP) technologies. This was observed, especially by the University of Central Lancashire (UCLan) that had incorporated a GSHP to one of its building. The GSHP is under performing due to the inefficient controls implemented with the GSHP. This paper proposes an intelligent multiagent building management system (MAS BMS) that aims to tackle this issue. Intelligence is provided by an ARTMAP, a type of artificial neural network that provides incremental learning inspired by how human process memory. Simulation results show the proposed intelligent MAS BMS is able to maximise the use of the GSHP effectively by profiling, predicting and coordinating its usage with other energy resources. The proposed method has performed better than the existing control strategies for the GSHP.
\end{abstract}

Keywords: Building management system, Multi-agent system, Artificial neural network, Intelligent energy management system.

\section{Introduction}

The need for intelligent energy system arises due to technological innovations that has resulted in the increasing demand for more energy to accommodate improving lifestyles. This has caused significant detrimental impact on the environment, specifically environmental changes.

To date, the major sources of energy for the UK are from nonrenewable carbon-based fuels, with almost $77 \%$ of electricity produced are from these sources [1]. High use of carbon-based fuels leads to high $\mathrm{CO}_{2}$ gas emission, contributing to global warming [1], [2]. Reducing the use of carbon-based fuels and substituting them with renewable energy sources may help reduce the $\mathrm{CO}_{2}$ gas emission [1], [2].

Intelligent systems are autonomous (or semi-autonomous) systems that have the ability to monitor their system behaviour and provide the necessary controls to increase efficiency. The use of intelligent controls may help optimise the use of renewable energy by (i) minimising energy waste and loss, (ii) optimising load control, and (iii) increasing and improving energy efficiency. This, in turn can maximise the use and benefits of renewable energy, which can help reduce the cost of energy usage as well as the $\mathrm{CO}_{2}$ gas emission and its effect to the environment.

Intelligent controllers are required to ensure efficient renewable energy usage, particularly when the building incorporates slow response renewable technologies, such as the Ground Source Heat Pumps (GSHP) [3]-[6]. Furthermore, a number of reports [7] - [10] have indicated that the reductions in predicted efficiency and the under performance of such technologies are due to unsuitable control mechanisms, i.e. non-intelligent controls strategies.

The University of Central Lancashire (UCLan) has its own example. The Samuel Lindow Building (SLB) at UCLan WestLakes Campus in Cumbria is installed with a GSHP that operates in addition to the conventional gas central heating system [11]. Despite this, the controller used to manage this renewable energy is not intelligent. Investigations of the output from the GSHP at UCLan's SLB indicate that the GSHP is under performing. This may have resulted from the inefficient nonintelligent control strategies of the existing building management system (BMS).

The existing BMS uses a Multi Agent System (MAS) approach with the rule-based mechanism. The rule-based mechanism lacks adaptiveness and flexibility of controls, which may have resulted in the under performing of the GSHP. This paper proposes a new MAS with a new intelligent and adaptive control strategies to manage the different heat sources in SLB, including the GSHP. The new MAS incorporates a computational intelligence algorithm (artificial neural network) that aims to improve and maximise the use of the GSHP in providing heat for the building. This is achieved by profiling, predicting and coordinating its usage with other energy sources, and in accordance to the heat demand required (also profiled and predicted).

The paper introduces a MAS BMS with ARTMAP, a type of ANN that adds intelligence to the MAS. The paper is divided into eight sections. Section 2 provides a brief summary of the existing MAS used for BMS as well as a brief introduction to 
the proposed ARTMAP. Section 3 describes the UCLan WestLakes Samuel Lindow Building (SLB). Section 4 describes the existing MAS BMS that is currently in place and in use to provide heat to the SLB. Section 5 presents the method proposed to help maximise the use of the GSHP for the SLB. Section 6 presents and discusses the case studies used to test and analyse the proposed method presented in Section 5. Section 7 describes the results of the case studies and Section 8 concludes the paper.

\section{Multi Agent System}

Multi-agent system (MAS) consists of two or more agents in an environment. Each agent has its own functions or goals, and interacts with each other in a peer-to-peer (decentralised or distributive) manner so as to achieve its collective goals or objectives. MAS is particularly suitable for the distributive control tasks in a building environment (MAS BMS) because of their distinctive advantages, such as modular structure, openness, self-capacities, self-organisation and high-level transparency [14] - [15]. For example, each room in the building will have its own individual room temperature and thermal comfort control that is independent of the boiler control system. Therefore, the room requires its own agent and the boiler system has another. Mutual agreement and decision making are achieved through communication between the agents in the building.

MAS alone, however, has low level on-line learning and adaptation capabilities. Recently, artificial neural network (ANN) and/or fuzzy techniques are incorporated to the agents of the MAS, with the goal of incorporating online learning and adaptation capabilities to the MAS and other performance improvements [15] - [17]. The examples of such incorporation are:

1. Fuzzy MAS BMS: Fuzzy logic is suitable for BMS because the objective of thermal comfort management may be referred to as the state of mind or psycho-synthesis of the occupants in a building environment that expresses satisfaction with the temperature in the building. This is fundamentally a fuzzy concept, which differs from people to people, and is dependent on the type of activities they are engaged in [18] - [22].

2. ANN MAS BMS: Liang [23] has developed a backpropagation ANN that is used to maintain the thermal comfort level within a desired range. However, due to the slow convergence of back-propagation, the controller may not be a feasible solution for large building environment.

3. Neuro-fuzzy Thermal Comfort Management: Neuro-fuzzy systems combine ANN and fuzzy techniques. Yamaha et. al. [24] has developed a neuro-fuzzy BMS to predict weather parameters and the number of occupants in a building. This predictive information are then used to profile the energy flow for the building in order to minimise energy consumption and to maintain thermal comfort at an acceptable level.

\subsection{Proposed Algorithm: ARTMAP}

This paper presents the use of ARTMAP to add intelligence and online learning to the MAS BMS. ARTMAP, which was developed by Carpenter et. al. [27], is a supervised artificial neural network (ANN) algorithm inspired by how human process memory, and is able to learn new information without necessarily forgetting previously learned information [27], [28]. ARTMAP deals with the stability and plasticity issues by combining two adaptive resonance theory $(A R T)$ networks, i.e. $A R T$ $a$ and $A R T b$, as illustrated in Figure 1, which have the ability to establish memory (the input-to-output correlations) within the two networks. A memory is created through the interconnection that transfers short term memory (STM) to and from long term memory (LTM) within each ART network [27], [28]. ARTMAP performs both prediction and classification, and is an ideal tool for online learning and adaptation of an agent.

ARTMAP works by classifying and categorising the inputs presented to the network at ART $a$ according to the desired categories (supervisory inputs) presented at $A R T b$ [27], [28]. During supervised learning, $A R T$ a receives the inputs that needed to be classified, whilst $A R T b$ indicates how the provided inputs should be classified. The two ARTs are linked by an associative memory, as illustrated in Figure 1. The associative memory consists of an associative map and a controller, called map field, that prevents category proliferations within ART $a$ [27].

The associative map does not directly associate inputs presented to ART $a$ and ART $b$, but instead creates the association between the category activation produced by $A R T a$ and $A R T b$ [27]. The map field uses a minimax learning rule that automatically links predictive success (the category activation produced by $A R T a$ ) that matches the category activation produced by $A R T b$. The learning rule is executed on a trial-by-trial basis, by increasing the vigilance parameter of $A R T a\left(\rho_{a}\right)$ with the minimum amount needed to make the corrective predictive error at $A R T b$ [27]. The smaller the $\rho_{a}$ value, the bigger the size of the category. This process is called match tracking, which sacrifices generalisation in order to ensure minimal predictive error [27]. If the predictive error persists, a new category will be created within $A R T a$, which correlates the new input patterns presented to $A R T a$ to the input (category) information presented to $A R T b$.

This architecture helps ARTMAP learn new data without forgetting its previously learnt information, as well as providing the ability to infer the adaptive output based on newly acquired memory [27], [28].

\section{UCLan Samuel Lindow Building}

UCLan Samuel Lindow Building (SLB) uses gas fired boilers and a Ground Source Heat Pump (GSHP) as heat sources for the building. As indicated in Section 1, the SLB heat distribution is controlled by a rule-based multi agent building management system (MAS BMS) that aims to maintain the temperature of the building zones at $23^{\circ} \mathrm{C} \pm 2^{\circ} \mathrm{C}$.

The current MAS BMS splits the building into 4 zones, with each zone controlled by an agent. The zones are: 


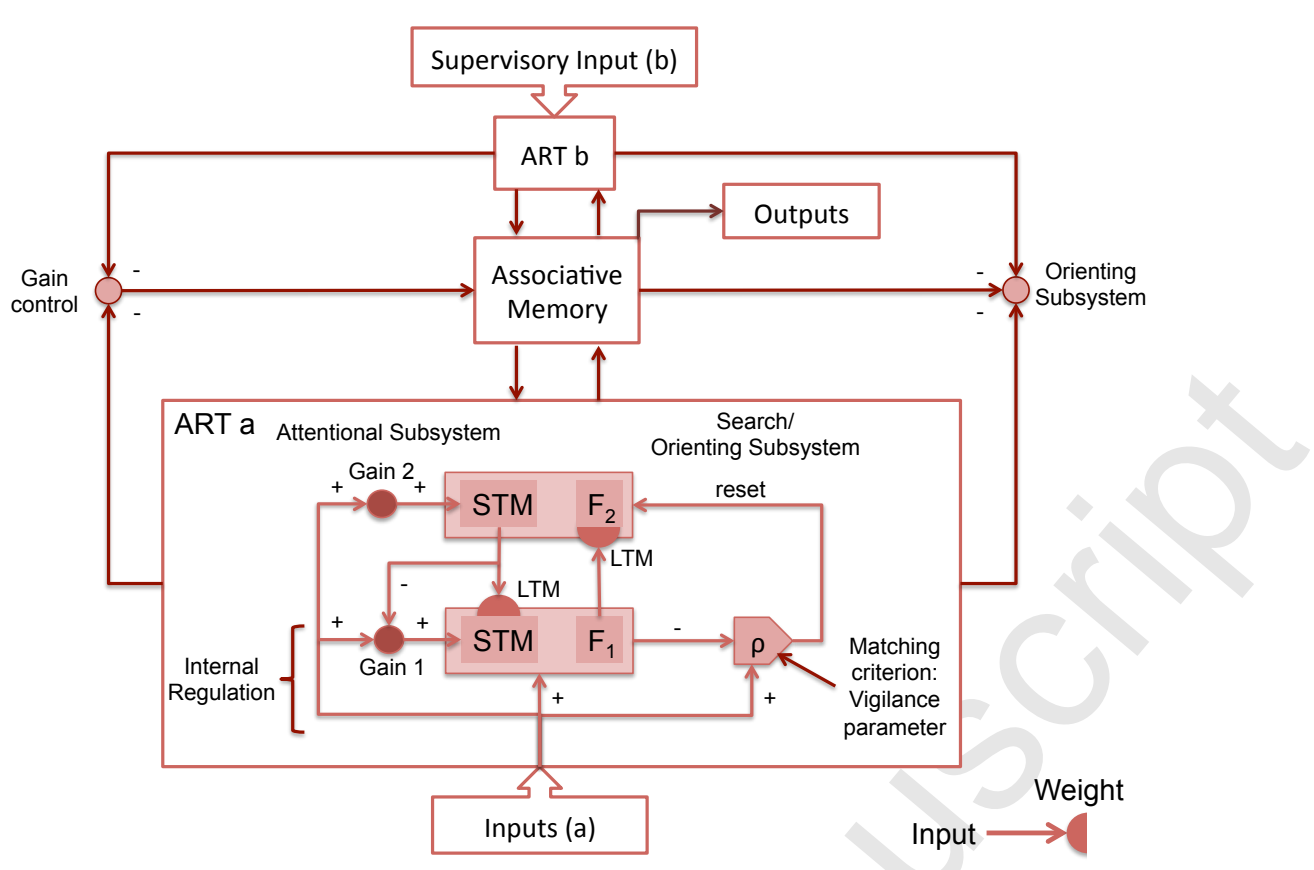

Figure 1: ARTMAP structure [27], [28].

1. Reception Zone: located on the ground floor and includes a cafe/restaurant area. The Reception Zone is shown in Figure 2, which also includes the area labelled the Open area zone.

2. BIU Zone: Business Incubation Unit (BIU) is also located on the ground floor and consists of one open work area and three small offices. BIU is shown in Figure 2.

3. Ground Floor Zone: This is the remainder of ground floor area and consists of a lecture theatre and various rooms on the ground floor, as shown in Figure 2.

4. First Floor Zone: consists of offices including a computer room, class rooms and a mezzanine/library floor.

The heat for Zones 2, 3 and 4 are provided by radiator panel(s) in each room in the zones, with the gas boilers providing the heat to the radiators. The heat for Zone 1 is provided by:

1. Underfloor heating (UFH), with the heat provided by the GSHP.

2. Five radiator panels, with the heat provided by the boilers.

We are limiting our analysis of the MAS BMS and subsequent application of the newly proposed MAS BMS controls to Zone 1 only. Further information on other zones are described in [17] and [25].

\subsection{Reception Zone}

The Reception Zone (Zone 1) is divided into seven subzones. Each sub-zone has a temperature sensor. Five out of the seven sub-zone temperature sensors monitor the sub-zones heated by the radiator panels, one per each sub-zone. The UFH provides heat to the remaining two sub-zones, with a temperature sensor installed at each of the two sub-zones.

\subsubsection{The Under Floor Heating System (UFH)}

The underfloor heating system or UFH is a sequence of nine loops of $40 \mathrm{~mm}$ plastic tubes arranged in parallel to cover the entire $165 \mathrm{~m}^{2}$ floor space of the room. The tubes are set $150 \mathrm{~mm}$ apart. The loops are arranged so that heating is applied evenly throughout the room as warm water passes along the length of the pipe in each loop.

The heat (warm water) for the UFH heating system is provided by the Visemann Vitocell 300-B 500l heat exchange vessel [12]. The exchange vessel uses two indirect coils to exchange heat via the water in the tank. The maximum heat output from the vessel is $15 \mathrm{~kW}$, pumped at a rate of $0.39 l \mathrm{~s}^{-1}$ by the UFH heating pump. Figure 6 (on page 7) shows the recorded water temperature of the exchange vessel. Heat is supplied to the exchange vessel from the Visemann Vitocell 300G Ground Source Heat Pump (GSHP) [13].

\subsubsection{Ground Source Heat Pump}

The GSHP works by pumping a fluid along pipes buried underground. The heat that may be extracted from the ground is dependent on the temperature of the ground, the size of the evaporation chamber and the capability of the pump. Figure 3 shows the relationship between the ground temperature and the heat that may be extracted (A), as well as the electrical power used by the heat pump to perform the evaporation, compression and condensing (C). The heat pump may be used for cooling, and this performance is shown by (B) in Figure 3. The performance of the heat pump depends on the temperature the fluid is raised to.

The system installed in the SLB is set to maximum $55^{\circ} \mathrm{C}(\mathrm{F})$, while better performance may be reached with lower temperatures $45^{\circ} \mathrm{C}$ (E) and $35^{\circ} \mathrm{C}$ (D). The maximum output from the GSHP is $29 \mathrm{~kW}$ for heating the brine to $55^{\circ} \mathrm{C}$ with very warm 


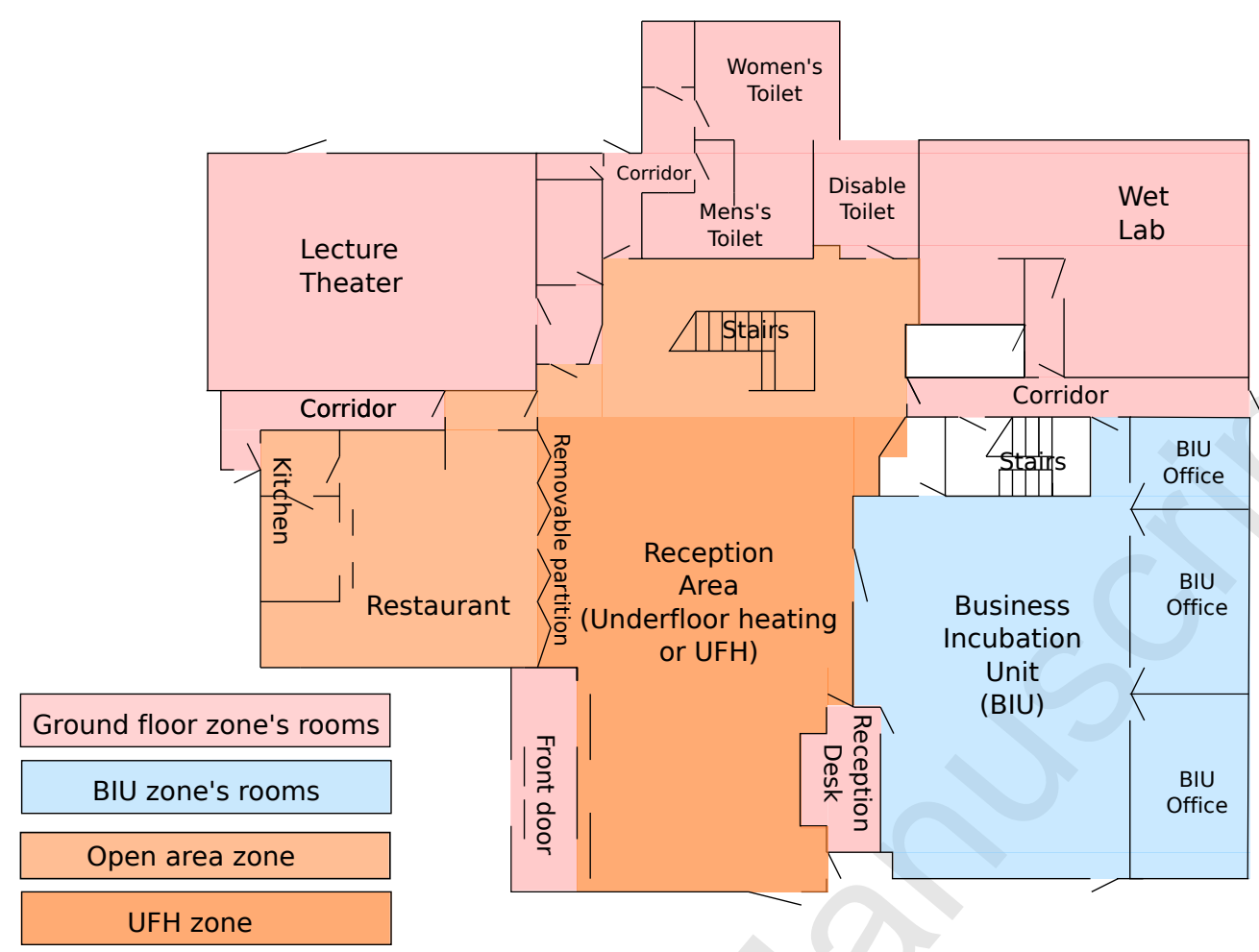

Figure 2: The schematic of the ground floor of UCLan Samuel Lindow Building.

ground temperature $\left(>15^{\circ} \mathrm{C}\right)$, but closer to $24.8 \mathrm{~kW}$ at a ground temperature at $\approx 8^{\circ} \mathrm{C}$. The electrical power used to achieve this is $\approx 7.6 \mathrm{~kW}$, giving a coefficient of performance $(\mathrm{CoP})$ of 3.26 . By comparison, the gas boilers may only be $85-92 \%$ efficient, therefore having far lower $\mathrm{CoP}$ values.

\section{The Existing Multi Agent Building Management System (MAS BMS)}

As described in Section 1, the existing building management system (BMS) uses a multi-agent system (MAS) to manage its heat distribution. The existing MAS BMS, illustrated in Figure 4, consists of User Agents and Source Agents. A User Agent is responsible for achieving and maintaining the desired temperature for each of its respective zone (Section 4.1). The Source Agent is responsible for describing how best to provide heat for the building (Section 4.2).

\subsection{User Agents}

In the existing BMS, the User Agents are incorporated with a set of rules (rule-based method) to ensure that the building is maintained within the desired temperature. The rules are:

If ( zone temperature $<$ desired temperature )

Then open the hot water valve to the zone to allow the hot water to flow to the radiators in the zone and the water temperature in the radiators to increase to approximately (maximum of) $80^{\circ} \mathrm{C}$;

Else
Then close the hot water valve and the water temperature in the radiators decreased and maintained at the decreased temperature until the zone temperature $=($ desired temperature $-2^{\circ} \mathrm{C}$ );

The hot water temperature to a zone decreases by mixing hot water from the boilers with the return water from the radiators in the zone.

The desired temperatures of the zone are:

If ( during the weekdays )

Then desired temperature $\approx 23^{\circ} \mathrm{C}$;

Else

Then desired temperature $\approx 10^{\circ} \mathrm{C}$;

\subsection{Source Agents}

The Source Agent for the boiler system states that:

If during the weekdays and between 02:00 to 21:00hr

Then the boilers are switched on and

hot water temperature $\approx 80^{\circ} \mathrm{C}$;

Else

Then the boilers are switched off and the water temperature from the boilers are cooled;

The Source Agent for the GSHP states that:

If ( zone temperature < desired temperature )

Then the GSHP is switched on;

Else

Then the GSHP is switched off; 


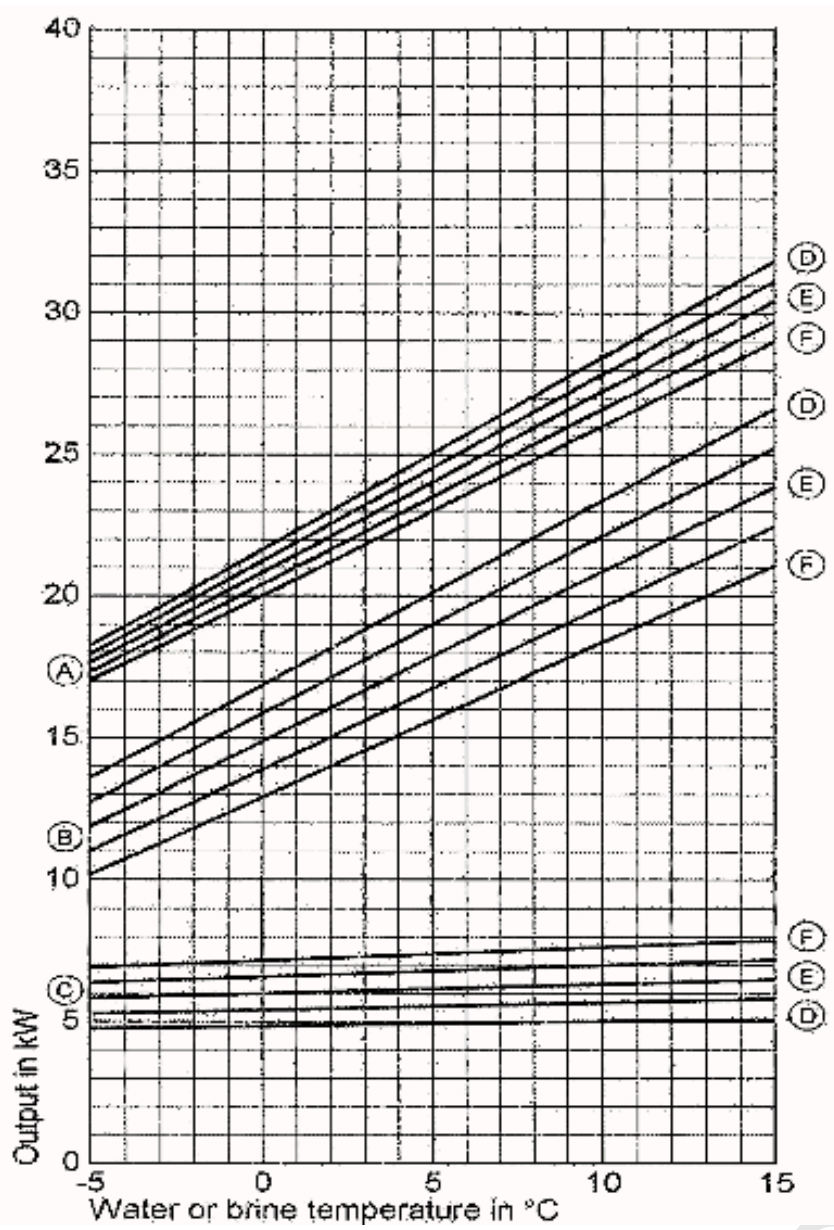

Figure 3: Performance of the Vitocell 300GHeat Pump [13]

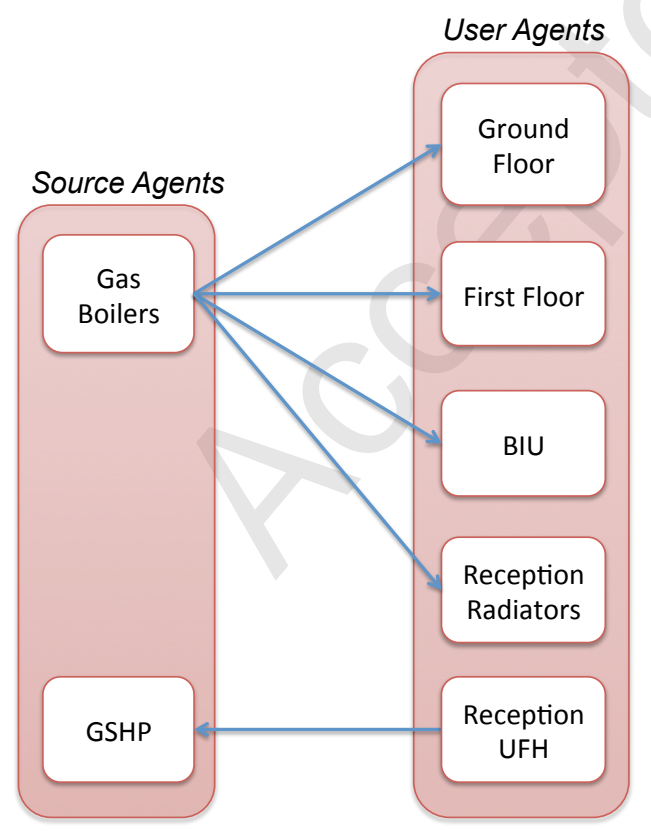

Figure 4: The multi-agent system of the UCLan SLB multi agent building management system or MAS BMS.
In the existing MAS BMS, there is only one-way communication between the Source Agent and the User Agents. The Gas Boilers Source Agent propagates the hot water temperature value to the User Agents, but no room temperature information is fed back to the Gas Boilers Source Agent from the User Agents. No communication is established between the two Source Agents, despite the two sources providing heat to the same zone (Reception Zone 1).

\subsection{Recorded temperatures}

The GSHP was installed to help reduce the energy bill for the building. Figures 5 and 6 show the recorded room temperature sensors from the seven sensors installed within the Reception Zone of the SLB and the recorded water temperature in the exchange vessel for the UFH.

Figure 5a demonstrates how the GSHP is under performing in providing heat to the Reception Zone 1, whereby the figure shows that for long periods of time, the temperature of the room is greater than the water temperature in the UFH tank. This is because during these periods, heat is provided by the five radiators connected to the gas central heating system. The existing MAS BMS allows heat to be provided by the gas boilers without considering the heat provided by the GSHP. This resulted in the heating system with faster response to provide the bulk of heat to the zone during the office hours. In Figure 5a, the GSHP is switched on when the water temperature values of the UFH system, labelled GSHP $\rightarrow$ UFH Water Tank in the figure, is greater than the zone temperature (approximately $>25^{\circ} \mathrm{C}$ ).

As can be seen in Figure 5b, the sub-zones temperatures with the radiators remain higher than the desired room temperature. This demonstrates that the gas boilers are the dominant heat source to the zone, when compared against the lower temperatures of the UFH system. This is because the radiators in the zone can draw heat faster from the gas boilers than from the GSHP; with their hot water constantly maintained at $\approx 80^{\circ} \mathrm{C}$. The gas boilers have provided a faster response to the heat demand from the zone.

In contrast, the water temperature of the exchange vessel to the UFH system is not maintained at a high temperature by the GSHP. The water temperature in the tank is only limited to $\approx 55^{\circ} \mathrm{C}$, once the system is switched on. The system is only switched on when there is a demand for heat from the zone. As a result, there is a far slower response from the GSHP to provide hot water for the UFH system. This is evident because, only at weekends that the UFH system is providing heat to the zone, i.e. providing heat when the gas boilers are programmed to be switched off. This is shown in Figure 6. The UFH system is indicated to provide heat to the zone when the water temperature provided to the UFH (indicated by GSHP $\rightarrow$ UFH Water Tank in Figure 6) is greater than the zone temperature. This indicates that the existing MAS BMS does not use the capabilities of the GSHP effectively.

Therefore, a new control approach is required to ensure the full utilisation of the GSHP. This may prevent the under performing of the GSHP and allows the building to achieve its initial objective of reducing its energy (gas) bills. 


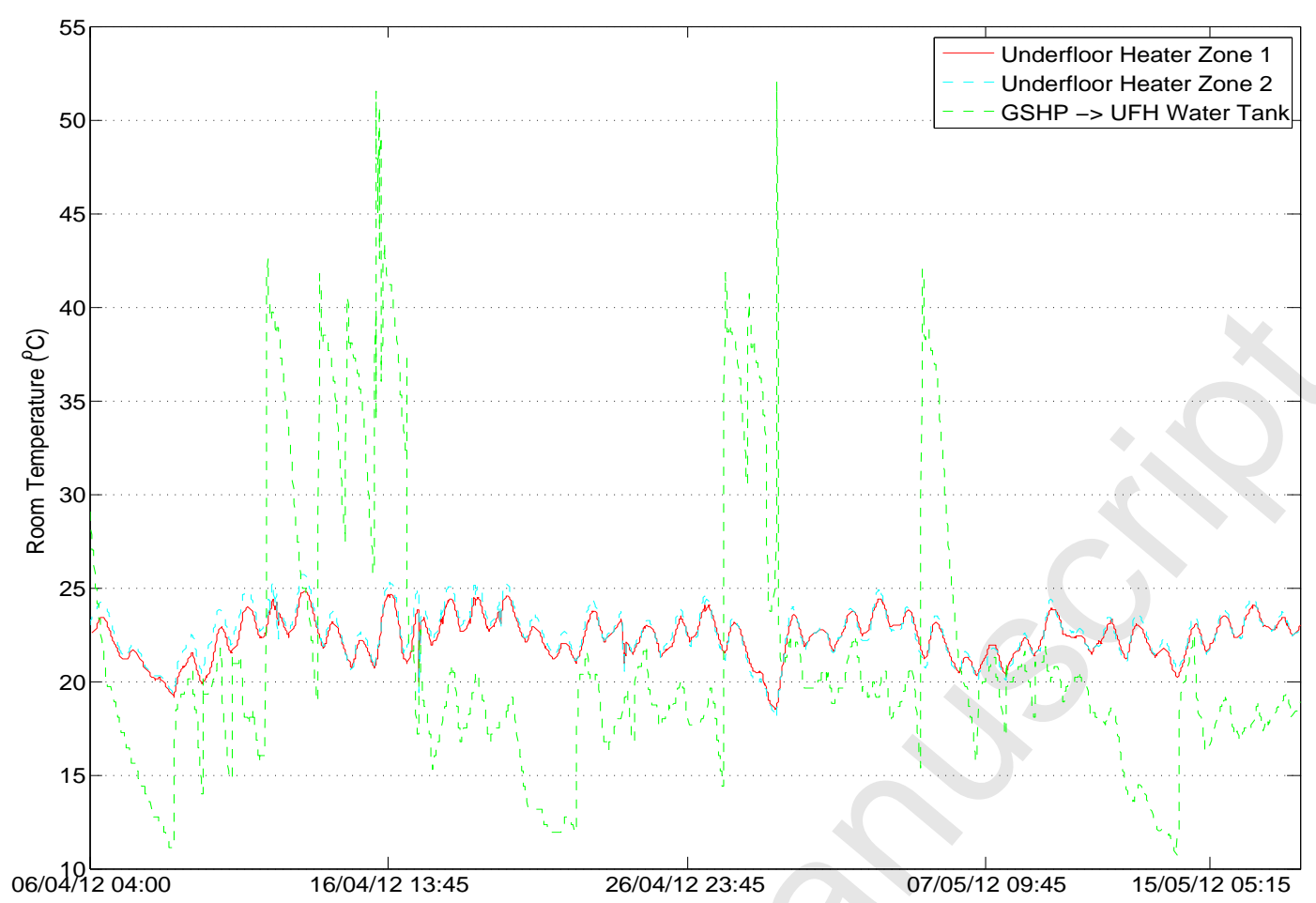

(a) The reading from the two sub-zones temperature sensors heated by the underfloor heating (UFH) system.

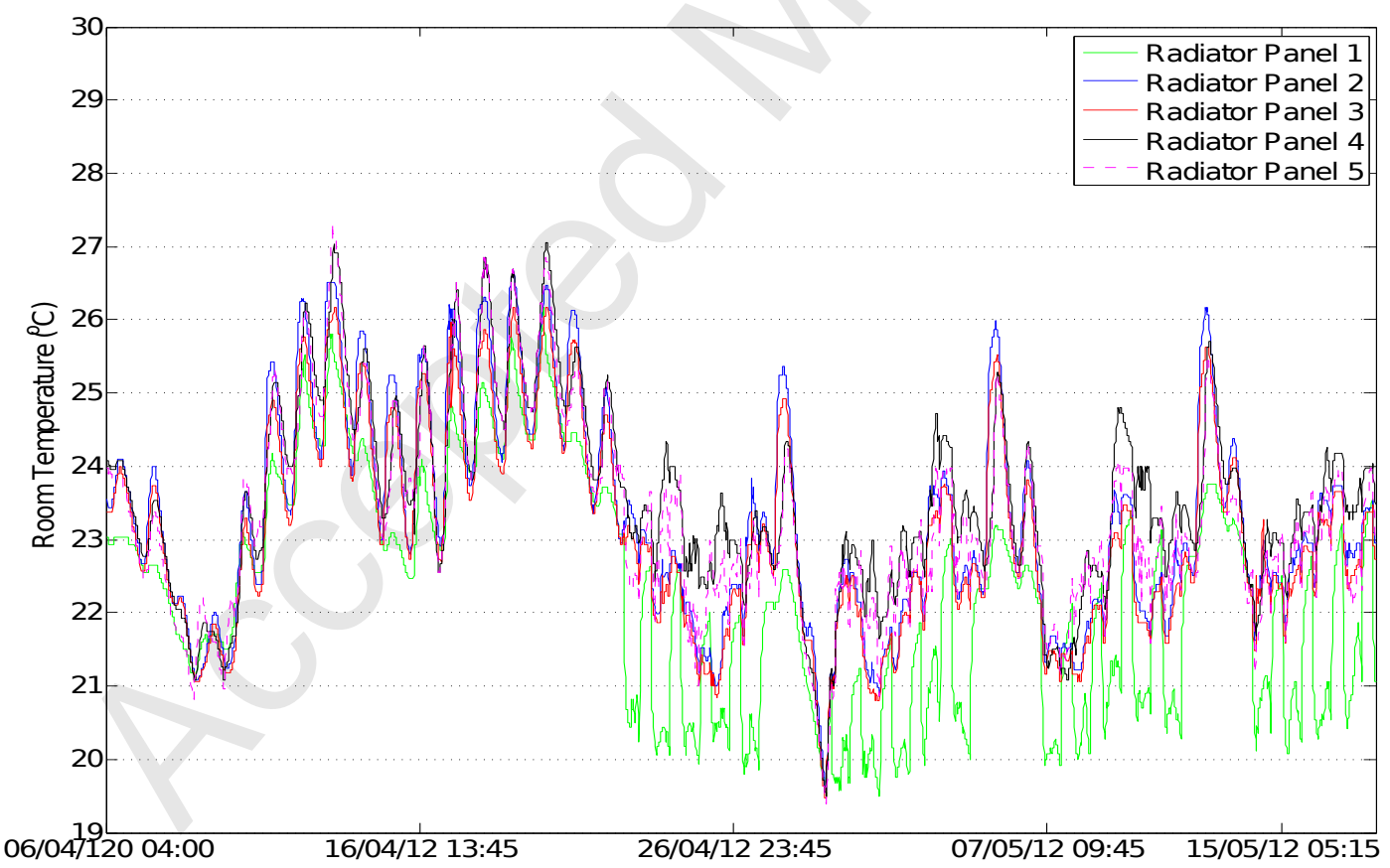

(b) The reading from the five sub zones temperature sensors, with each sub-zone is heated by a radiator and is within the area labelled the Open area zone.

Figure 5: The recorded room temperatures from the seven sensors installed in the Reception Zone (Zone 1) of the SLB shown in Figure 2.

\section{The Need for New Intelligent Control Strategies}

Qiao et. al. [16] presents a MAS incorporating mediator agents as intermediary agents that acknowledge and mitigate the transfer of information between User Agents and Source
Agents. The incorporation of Mediator Agents to our MAS BMS can help maximise the use of the GSHP and reduce the demand of energy from the gas boilers. The Mediator Agents can categorise the two heat sources for Reception Zone 1 into (i) 


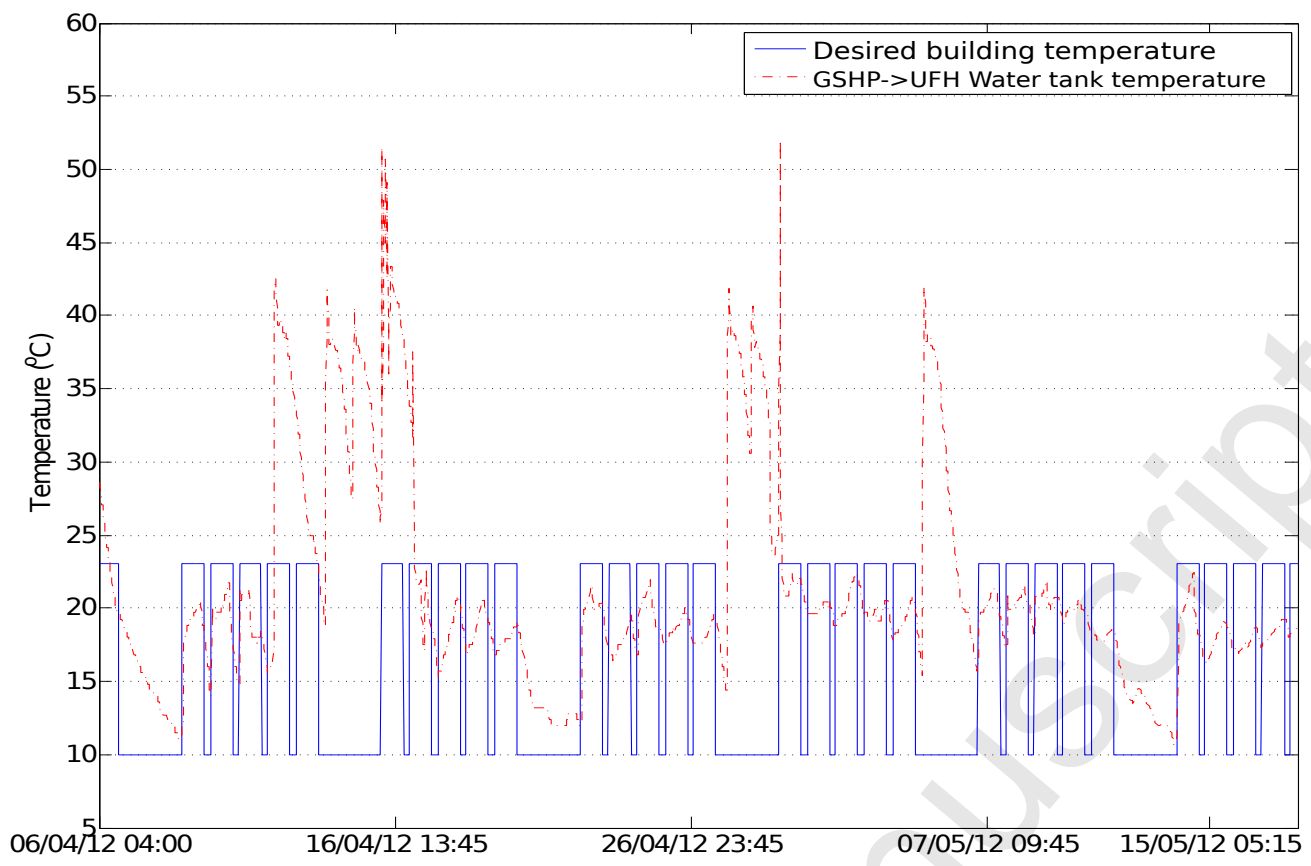

Figure 6: The recorded (hot) water temperature in the exchange vessel heated by the GSHP.

primary energy demand provided by GHSP and (ii) secondary provided by the gas boilers. The Mediator Agents can mediate when additional heat required by the Reception Zone is indicated and is to be provided by the secondary gas boilers.

Figure 7 illustrates the proposed MAS BMS that incorporates the mediator agents. This proposed MAS BMS is an extension to the BMS system for SLB described in [17] and [25]. The new BMS allows bi-directional communication between the Source Agents and the Users Agents in the building, mediated by the mediator agents. In the figure, Mediator Agent(ii) informs Mediator Agent(iii) when its respective User Agent(s) can participate with the heat management performed by the boiler's Source Agent.

Results presented in [17] and [25] show that the bidirectional communication between the two agents as well as the incorporation of ARTMAP to the agents can increase the energy efficiency of the building ${ }^{1}$. The control strategies required for the gas boilers and the radiators are dependent on the information provided by both the Source Agents and User Agents.

\subsection{The Need for Mediator Agents}

The Mediator Agent(ii) is required to help categorise the two heat sources into the two categories: (i) primary and (ii) secondary heat sources. This is as illustrated in Figure 7, which categorises the Reception Radiators User Agent as a passive system. The Reception Radiators User Agent does not propagate and influence the heat demand from the boilers, unless

\footnotetext{
${ }^{1}$ In [17] and [25], we omitted the Reception zone in our analysis. This is valid with the assumption that there is no heat transfer between the zones.
}

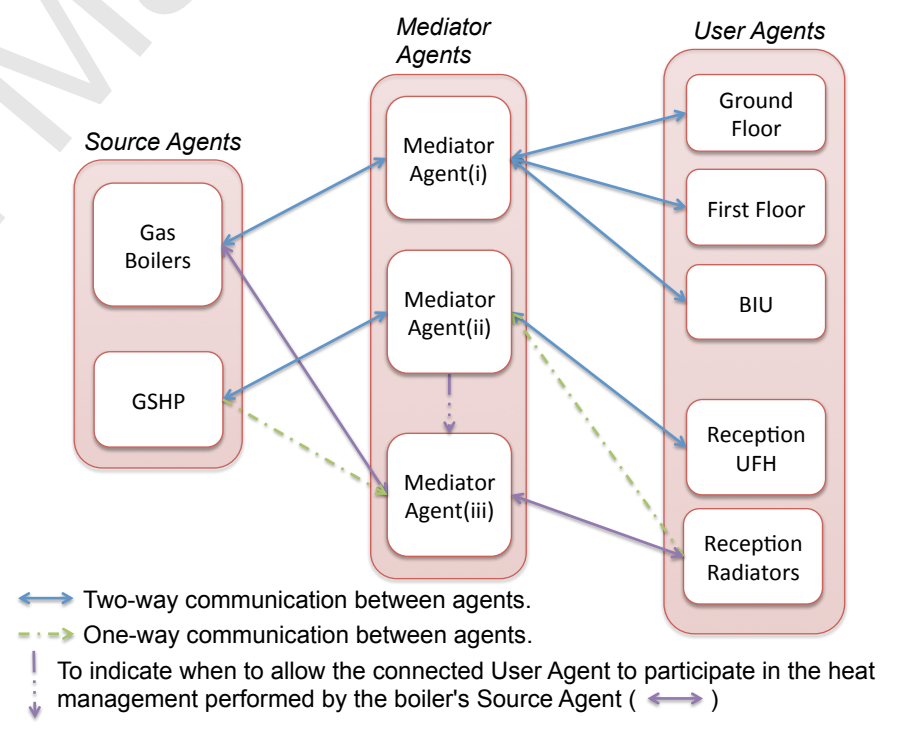

Figure 7: The proposed infrastructure of the MAS BMS with the Reception Zone (Zone 1) heat management performed by its respective User Agents.

allowed by Mediator Agent(ii). The transfer of heat demand information from the Reception Radiators User Agent to the Gas Boilers Source Agent is via the mitigation of the Mediator Agent(iii).

Because of this arrangement, the GSHP will be the main heat provider to this zone, with Mediator Agent(ii) as the main communication link between the heat sources (Gas Boilers and GSHP) and the heat users (Reception Zone). Mediator Agent(iii) will allow the Reception Zone Radiators User Agents to be active, similar to the other zones in the building, only 
when fault occurs to the GSHP and/or when additional heat is required by the zone.

\subsection{Adding Intelligence}

To allow the full utilisation of renewable energy technologies, the Intelligent mechanism is also required. Intelligence includes, but is not limited to, predictive and regulative capabilities in describing its required functionalities. The Intelligent mechanism will be installed to a microprocessor for each agent. Communication is proposed via the power line communication.

The following section describes how Intelligence are incorporated with the proposed MAS BMS illustrated in Figure 7.

\section{Case Study: Simulation of the SLB and the Proposed Building Management System}

To test the proposed MAS BMS shown in Figure 7, a model of the heating systems of the SLB, initially presented in [17] and [25], is used. The model is modified to include heating of the Reception Zone. This model will be simulated with three scenarios:

1. Scenario 1: Using the recorded (actual) hot water temperature as the heat source for all the zones (to omit the boiler controls simulation) and with the inclusion of the GSHP as another heat source to Zone 1. Heat management of the building is provided by the existing MAS BMS control strategies described in Section 4.

2. Scenario 2: Reception Radiator User Agent as a passive agent, and the Gas Boilers Source Agent is incorporated with new boiler controls. More information on the new boiler controls is described in Section 6.1.1. The new boiler controls, initially presented in [17], use the demand information only from Zones 2, 3 and 4 provided by the Mediator Agent(i). This is as indicated in Figure 7,

3. Scenario 3: The proposed MAS BMS using the infrastructure illustrated in Figure 7.

Each MAS BMS is simulated to manage the heat distribution of the SLB. Further description of Scenarios 2 and 3 are described in Sections 6.1 and 6.2 respectively. The results of these simulations are presented in Section 7.

\subsection{Scenario 2: New boiler controls and the Reception Radia- tors User Agent as Passive Agent}

In Scenario 2, new boiler controls are provided by the ARTMAP (added to the Gas Boilers Source Agent - Section 6.1.1). This arrangement is made to test the capabilities of the ARTMAP to provide new and improve boiler controls according to the dynamic heat demand from Zones 2, 3, and 4 (the hot water is heated to $\approx 80^{\circ} \mathrm{C}$ only when Zones 2,3 , and 4 demand the heat).

In this scenario, no heat demand information from the five radiators in the Reception Zone 1 are included in the decision making process of the Gas Boilers Source Agent. This forces the Reception Radiators User Agent to become a passive agent.
Reception Radiators User Agent is a passive agent to help overcome the under performing of the GSHP and to encourage its usage. As a passive agent, the Reception Radiators are not allowed to demand for more heat from the gas boilers. This is illustrated in Figure 7.

Scenario 2 is also created to indicate how much heat is required from only the Reception Zone. Results from Scenario 2 are compared against our previous work described in [17] that omits the Reception Zone from its simulation. The differences show how much heat can be saved if such heat was to be provided by the GSHP instead. This in turn helps in the energy saving of the building.

The User Agents use the rule-based mechanism that is currently in use within the existing MAS BMS (Section 4).

\subsubsection{New boiler controls}

At present, the Gas Boilers are not controlled by the dynamic heat demand of the building. This is as indicated in Section 4.2. The new Gas boiler controls provided by the ARTMAP can help reduce energy wasted due to the unnecessary heating of the boilers when there is no heat demand from the building and/or excess heat generation. The Source Agent uses the information provided by the User Agents under the mitigation of Mediator Agent(i), to provide the best operation of the boilers. The inputs to the Source Agent are:

1. Current date and time.

2. $O_{T}(t), O_{T}(t-1), O_{T}(t-2), O_{T}(t-3), O_{T}(t-4)$ :

$O_{T}(t)$ is the current outdoor temperature.

$O_{T}(t-x)$ is the outdoor temperature at the previous $x$ sample.

3. $I_{y}(t), I_{y}(t-1), I_{y}(t-2), I_{y}(t-3), I_{y}(t-4)$ :

$I_{y}(t)$ is the current average building temperature.

$I_{y}(t-x)$ is the average building temperature at the previous $x$ sample.

Average building $y$ temperature is calculated by averaging the measured temperature values of all zones in the building.

4. $W_{O}(t), W_{O}(t-1), W_{O}(t-2), W_{O}(t-3), W_{O}(t-4)$ :

$W_{O}(t)$ is the current average return water temperature from the radiators.

$W_{O}(t-x)$ is the average return water temperature from the radiators at the previous $x$ sample

5. $W_{I}(t), W_{I}(t-1), W_{I}(t-2), W_{I}(t-3), W_{I}(t-4)$ :

$W_{I}(t)$ is the current water temperature from the boiler.

$W_{I}(t-x)$ is the input water temperature from the boiler at the previous $x$ sample

(1) - (3) are the inputs indicating the energy demand. (4) - (5) are the inputs indicating the energy resource.

The outputs from the ARTMAP are:

1. ' 0 ' - boiler is switched off or ' 1 ' - boiler is switched on (labeled as mARTMAP1 in Figure 8 [17]).

2. The learned ideal hot water temperature to be maintained (and boiled) by the boilers.

3. The learned desired building temperature to be maintained. 
The Source Agents (the Gas Boilers and the GSHP) provide their outputs every fifteen minutes.

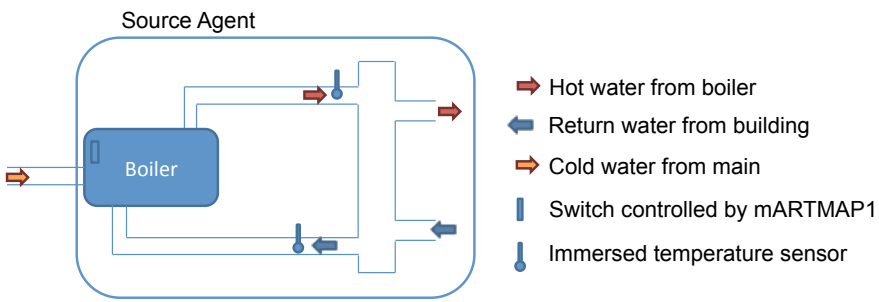

Figure 8: The Gas Boilers Source Agent responsible for the boiler management.

\subsection{Scenario 3: The Proposed MAS BMS}

The MAS BMS presented in [17] and [25] aim to achieve energy efficiency by minimising energy loss and energy bills of the building. The presented MAS helps increased energy efficiency through the:

1. Bi-directional communication between the User Agents and Source Agents.

2. New gas boiler controls provided by its Source Agent (as described in Section 6.1.1), which utilises demand information from the User Agents in its decision making strategies.

\subsubsection{Mediator Agents}

The two additional mediator agents (Mediator Agent(ii) and Mediator Agent(iii)) allow an indication of when the Reception Radiator's User Agents should become active and provide hot water to the five radiator panels in the zone. This allows the GSHP to become the primary heat provider to the zone. The mitigation of controls are managed through the communication between the two Mediator Agents.

To decide when the Reception Radiators User Agent should become active, Mediator Agent(ii) will utilise the following input information from the GSHP:

1. Is there hot water flowing from the GSHP, and

2. The water temperature from the boilers.

These sensors are installed and currently under-used by the existing MAS BMS of the building.

Inputs to the Mediator Agent(ii) are:

1. Current date and time.

2. $O_{T}(t), O_{T}(t-1), O_{T}(t-2), O_{T}(t-3), O_{T}(t-4)$.

3. $I_{T}(t), I_{T}(t-1), I_{T}(t-2), I_{T}(t-3), I_{T}(t-4)$.

4. $W_{I}(t), W_{I}(t-1), W_{I}(t-2), W_{I}(t-3), W_{I}(t-4)$.

5. $W_{O}(t), W_{O}(t-1), W_{O}(t-2), W_{O}(t-3), W_{O}(t-4)$.

6. $W_{G S H P}(t), W_{G S H P}(t-1), W_{G S H P}(t-2), W_{G S H P}(t-3)$, $W_{G S H P}(t-4)$ :

$W_{G S H P}(t)$ is the current water temperature to the UFH.

$W_{G S H P}(t-x)$ is the water temperature to the UFH at the previous $x$ sample.

(1) - (5) are the inputs indicating energy demand and (6) indicating the energy resource.

Outputs from the Mediator Agent(ii) are:
1. Either ' 0 ' for no hot water flow or ' 1 ' for full hot water flow to the radiators.

2. The learned desired temperature setting for the Reception Zone.

Similar to the Source Agent described in Scenario 2 and the agents presented in [17] and [25], the Mediator Agent(ii) provides its outputs every fifteen minutes. The above information is forwarded to the Mediator Agent(iii) to indicate when the Reception Zone User Agents can propagate its demand information to the Source Agent Gas Boilers.

\subsubsection{Adding the Intelligent capabilities}

The proposed MAS BMS incorporates the ARTMAP, described in Section 2.1, to provide intelligence to its active agents.

\section{Results}

As listed in Section 6, three sets of simulations conducted are:

1. Scenario 1: Existing BMS (Section 7.1): Scenario 1 uses the recorded (actual) hot water temperature as the heat source for all the zones. This is to omit the boiler controls simulations. Heat management of the Reception Zone 1 is provided by the existing rule-based MAS BMS control strategies indicated in Section 4.1.

2. Scenario 2: New boiler controls and the Reception Radiators User Agent as Passive Agent (Section 7.2): Reception Radiators utilise the hot water provided by the Gas Boilers Source Agent new boiler controls presented in Section 6.1.1, without the Reception Radiators User Agent be part of the decision making process of the boiler controls.

3. Scenario 3: Proposed MAS BMS (Section 7.4): The proposed MAS BMS described in Section 6.2.

All these scenarios are simulated with the recorded outdoor temperature indicated in Figure 9. The outdoor temperature is between $5^{\text {th }}$ March 2012 to $25^{\text {th }}$ May 2012, omitting the values between $22^{\text {nd }}$ March 2012 09:00 to $24^{\text {th }}$ March 2012 22:25. This is because no data was collected during these times.

\subsection{Scenario 1: Existing BMS}

Figure 10 shows the heat demand from the gas boilers reaches and maintains the desired temperature at the Reception Zone, given the outdoor temperature indicated in Figure 9. No heat output from the GSHP is shown, which resulted from the inefficiency of the existing MAS BMS in utilising the GSHP to meet the demand of heat from the zone. The GSHP is not providing any heat to the zone because the five radiators in the zone are the primary heat provider to the zone. This finding corroborates with the actual system shown in Figure 6.

The existing MAS BMS control strategies resulted in the five radiators in this zone to be the main heat provider to the zone (as shown in Figure 10). This causes the under performing of the GSHP. The intake of the hot water, demanded by the five radiators, should have been provided by the GSHP; which was the main purpose for the GSHP installation. 


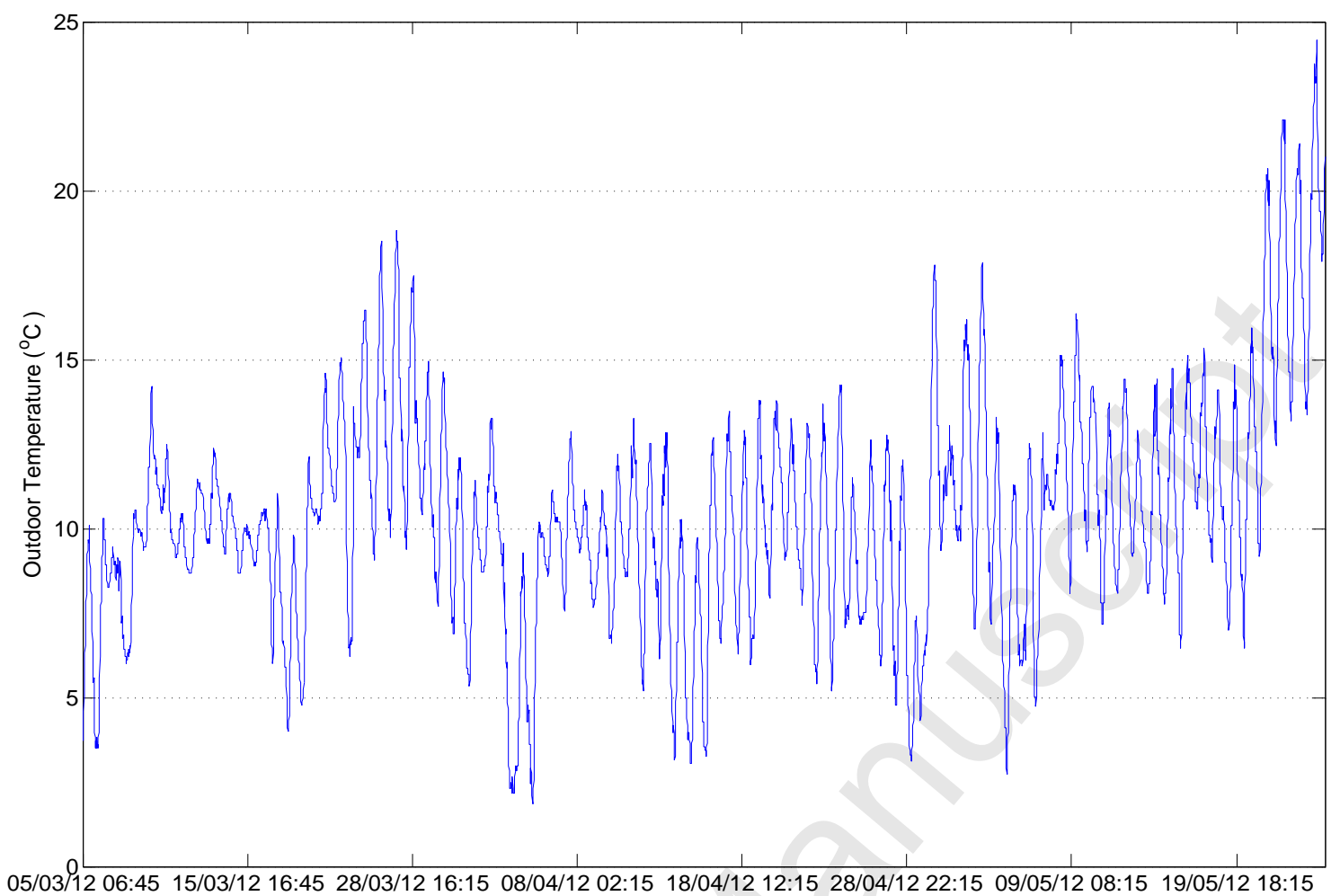

Figure 9: The recorded outdoor temperature between $5^{\text {th }}$ March 2012 to $25^{\text {th }}$ May 2012, omitting the hours of 22 $2^{\text {th }}$ March 2012 09:00 to 24 $4^{\text {th }}$ March 2012 22:24. No data were collected during these times.

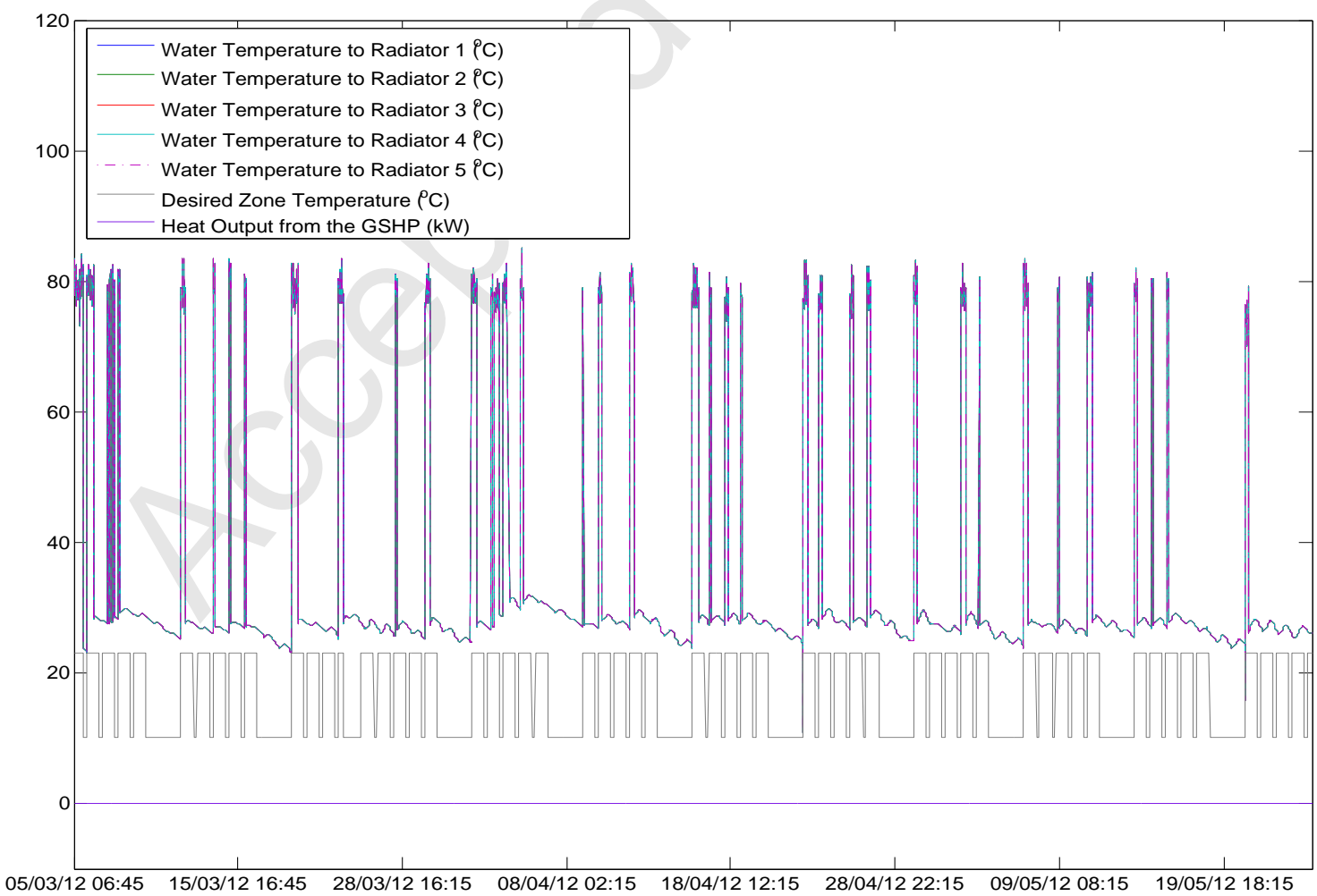

Figure 10: The water temperature provided to the five radiators in Reception Zone, the desired zone temperature and the GSHP heat output from Scenario 1. 


\subsection{Scenario 2: Reception Radiators User Agent as Passive Agent}

Figure 11 shows the distribution (box plot) of the simulated sub-zone temperatures minus the desired zone temperature when the Reception Radiators User Agent is a passive agent and the new boiler controls described in Section 6.1.1 are used. Similar simulated zone temperature values were recorded when compared against the two MAS BMS strategies: Scenarios 1 and 2 .

Despite treating the Reception Radiators User Agent as a passive agent, the results demonstrate that the heat provided can achieve and maintain the desired zone temperature, with less gas used and energy produced by the gas boilers. Heat is provided by the hot water produced by the new boiler controls. This is in comparison to actual energy (heat) consumption of the building, as indicated in Table 1. The difference between the actual boiler temperature and the boiler temperature resulting from dynamic heat demand from the building with new boiler controls is illustrated in Figure 13. Similar observation was described in [17] and [25].

\subsection{Summarising the Results from Scenarios 1 and 2}

Figures 10 and 12 show that because of the slow response time of the GSHP, the GSHP is not acting as the primary heat source to the Reception Zone; even with the Reception Radiators User Agent as passive agent (Scenario 2). No heat is provided by the GSHP because the five radiators in the zone are providing the required heat for the zone.

This indicates the need for the new MAS BMS strategies required to force the GSHP to become the primary heat provider for the zone. The new MAS BMS is presented in Section 6.2 and illustrated in Figure 7. Results from the new BMS Intelligent control strategies are presented in the following section.

Table 1: Comparing the Energy Usage with New Boiler Controls.

\begin{tabular}{l|c}
\hline & Energy used (MWh) \\
\hline Existing BMS & $55.009^{\mathrm{b}}$ \\
\hline $\begin{array}{l}\text { With new boiler controls } \\
\text { (Section 6.1.1) } \\
\text { without the Reception zone }\end{array}$ & $27.0839^{\mathrm{b}, \mathrm{c}}$ \\
\hline $\begin{array}{l}\text { With new boiler controls } \\
\text { with the Reception zone }\end{array}$ & $39.1618^{\mathrm{c}}$ \\
\hline $\begin{array}{l}\text { Heat required by the Reception } \\
\text { zone }\end{array}$ & $\begin{array}{c}39.1618-27.0839 \\
=12.0779\end{array}$ \\
\hline \hline
\end{tabular}

a The actual energy used by the building between $1^{\text {st }}$ March to $25^{s t}$ May 2012. Information is estimated based on the information provided by the energy provider $e$.on and the installed BMS.

b Data collected from [17].

c Energy used is measured using the temperature differences between the provided hot water to the zone and its return water temperature.

\subsection{Scenario 3: The Proposed MAS BMS}

The new proposed BMS strategies adds Intelligence (ARTMAP) to all the active User Agents and to its Gas Boilers Source Agent in the MAS BMS. This is because these agents are easily replaceable from the existing BMS. Figure 14 shows the distributions of the simulated sub-zone temperatures for the Reception Zone when its heat is managed by the proposed MAS BMS illustrated in Figure 7.

Figure 14 shows Intelligence, provided by the ARTMAP, added to the GSHP User Agent helps ensure that the GSHP is the primary heat provider to the Reception Zone. The GSHP has produced part of the required 12.0779MWh heat required by the zone. This is as indicated in Table 1. The GSHP has provided the heat output of $\approx 11.7660 \mathrm{MWh}$, which is equivalent to $97.5 \%$ of the energy required to heat the Reception zone. In doing so, the GSHP used 3.36MWh of electrical energy. This demonstrates a system efficiency of $\geq 349 \%$.

The greater use of the GSHP with the improved boiler controls have resulted in a $23 \%$ reduction in the building's gas consumption. This can lead to lower carbon emissions and greater energy cost savings. Increased revenues may be achieved with the addition of Renewable Heat Incentive payments from UK government [31].

The performance of the GSHP means that the carbon cost of the grid electricity used to power the heat pump is less than that equivalent heat energy from the gas supply. This further contribute to the lowering of the carbon emissions.

Table 2: Comparing the Energy Usage with the Proposed MAS BMS

\begin{tabular}{l|c}
\hline & Energy used (MWh) \\
\hline Existing BMS & 55.0090 \\
\hline With the proposed MAS BMS & $38.6796^{\mathrm{a}}$ \\
\hline \hline Electricity used by the GSHP & 3.36409 \\
\hline \hline
\end{tabular}

a Energy used is measured using the temperature differences between the provided hot water to the zone and its return water temperature.

\section{Summary \& Conclusion}

The existing multi agent building management system (MAS BMS) at the UCLan Samuel Lindow Building (SLB) shows that without the intelligent control strategies, the advantages of incorporating its ground source heat pump (GSHP) energy technology are not manifested.

This can be addressed by adding intelligence to the MAS BMS. ARTMAP, a type of artificial neural network (ANN), was introduced to address this issue. The ARTMAP provides the intelligent capabilities to User Agents and the Source Agents of the MAS BMS. This is to allow heat sources to provide heat based on the dynamic heat demand of the building.

Simulation results presented in this paper show how a MAS BMS with intelligence incorporated to its User Agents and 


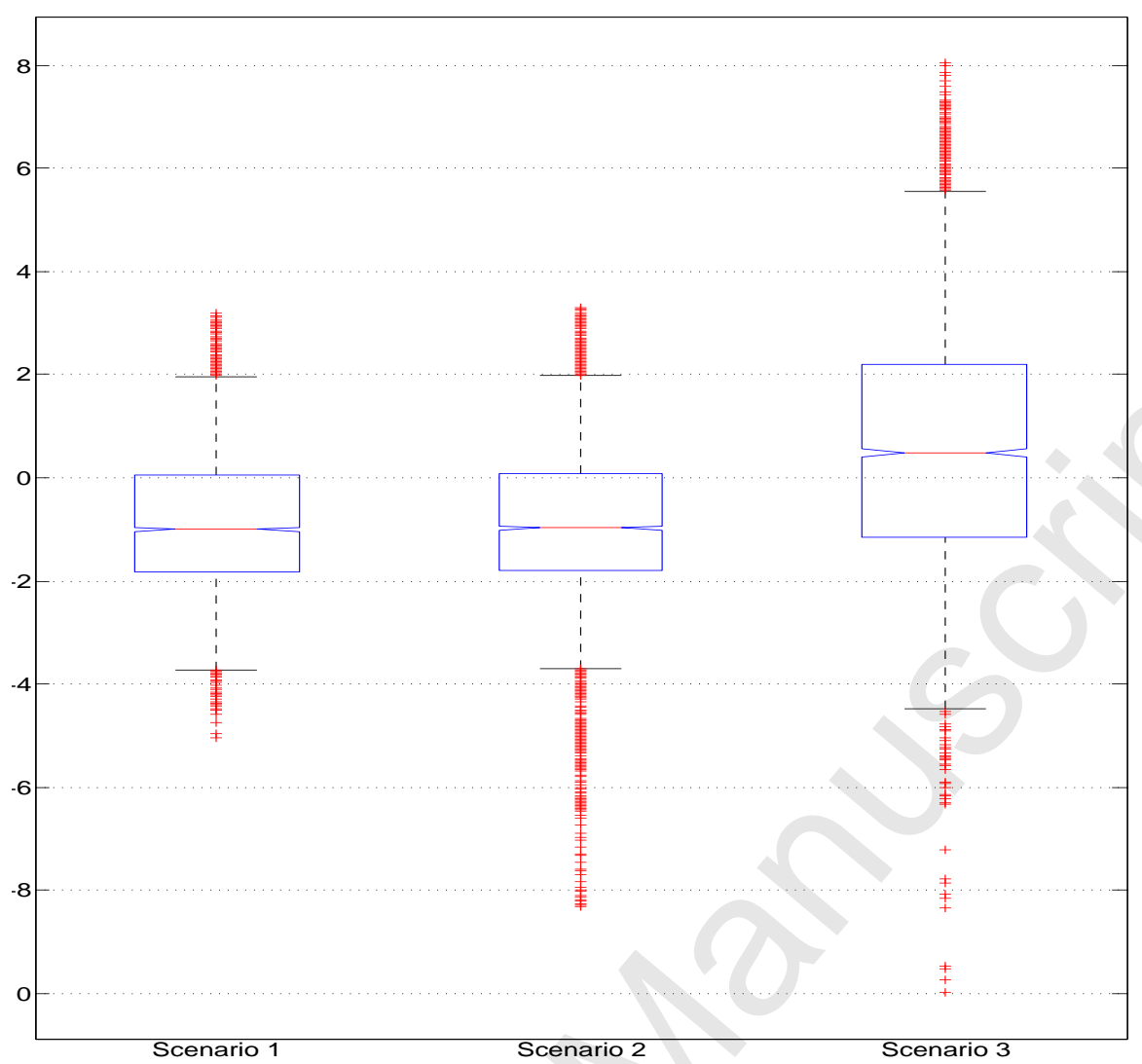

Figure 11: The distribution (box plot) of the average Reception Zone 1 temperature minus the desired temperature for Scenarios 1, 2 and 3.

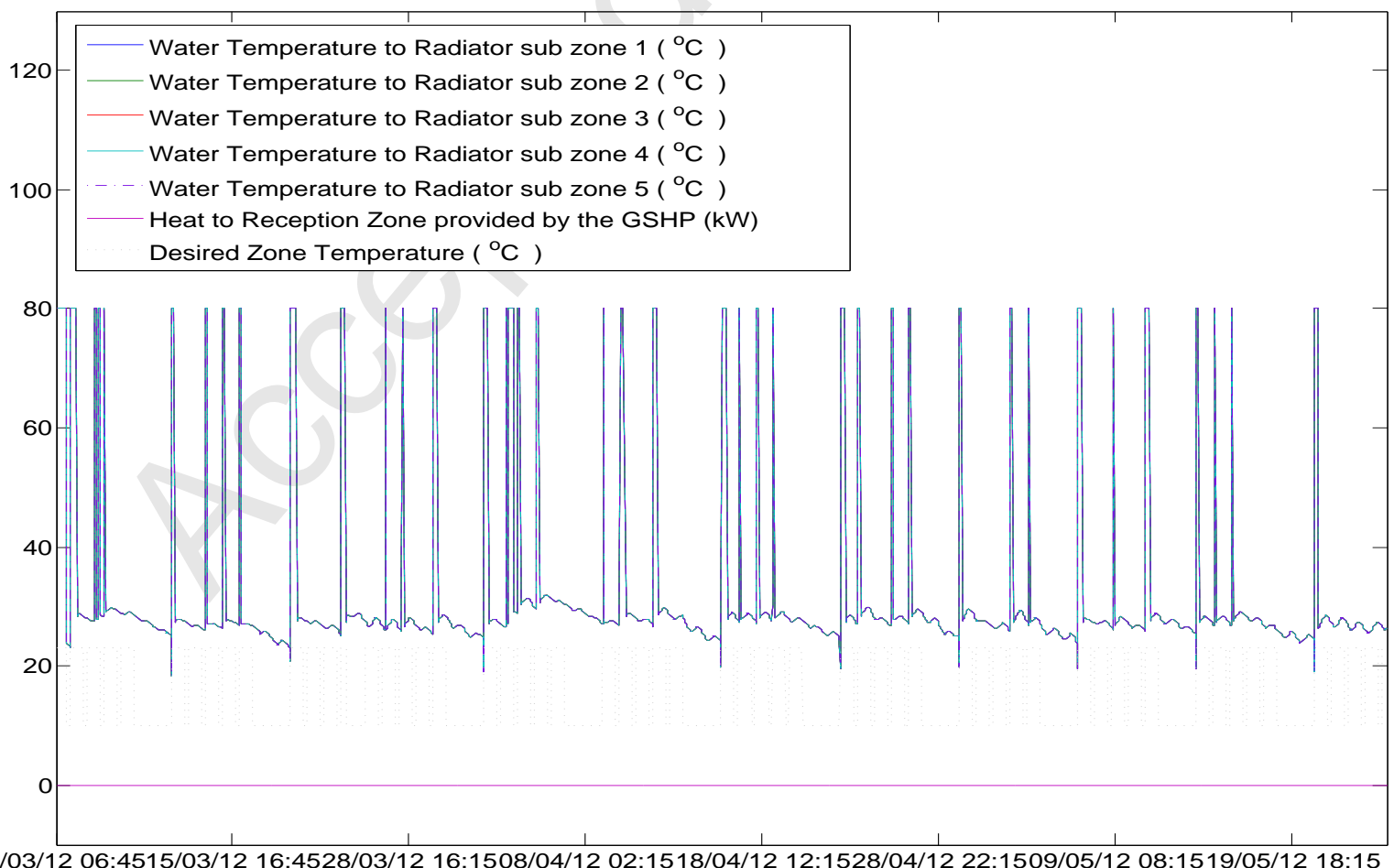

Figure 12: The water temperature provided to the radiators in Reception Zone, the desired zone temperature and the GSHP heat output to the zone from Scenario 2. 


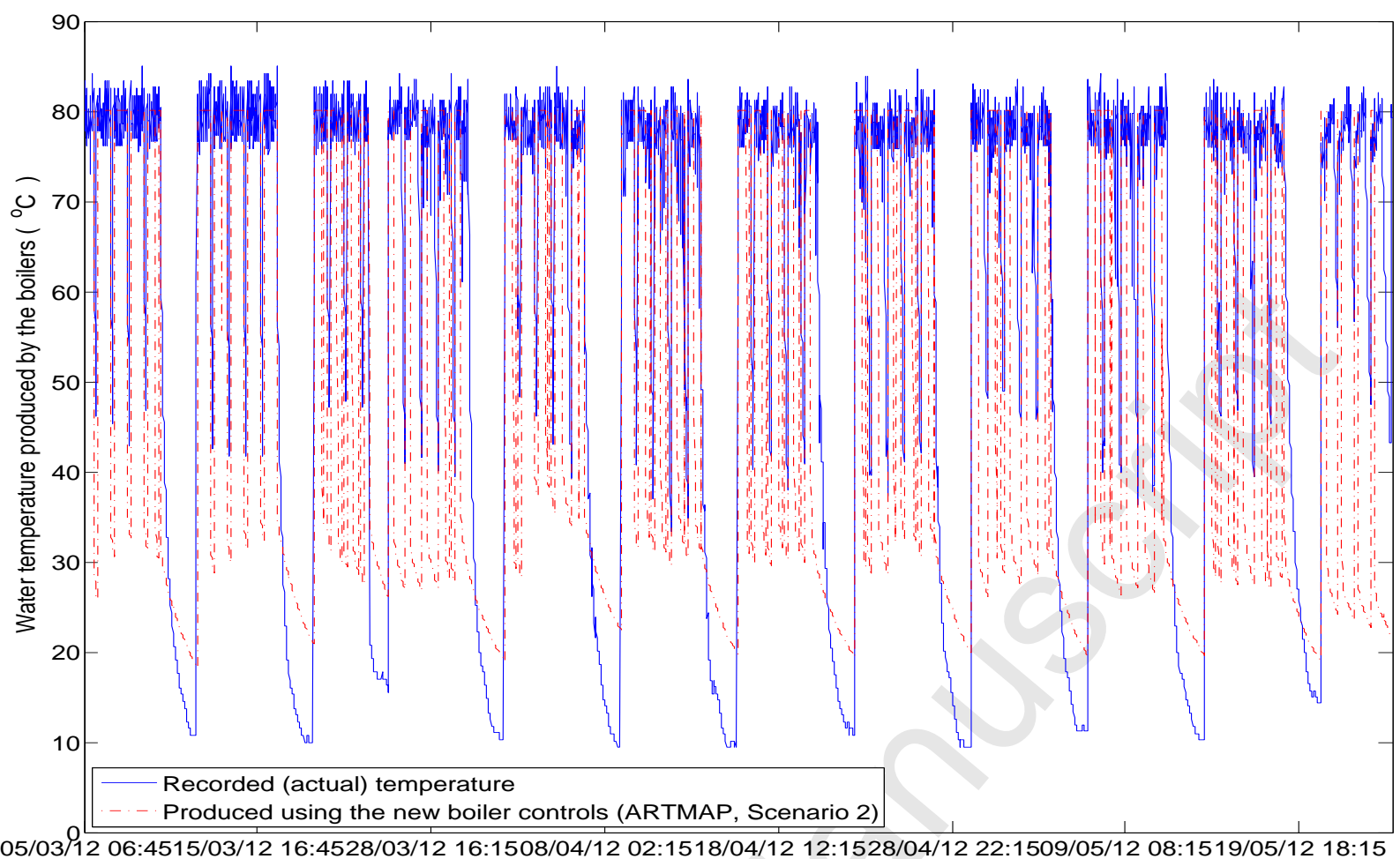

Figure 13: The hot water temperature produced by the gas boilers when utilising the MAS BMS control strategies described in Section 6.1 (Scenario 2) and the actual hot water temperature.

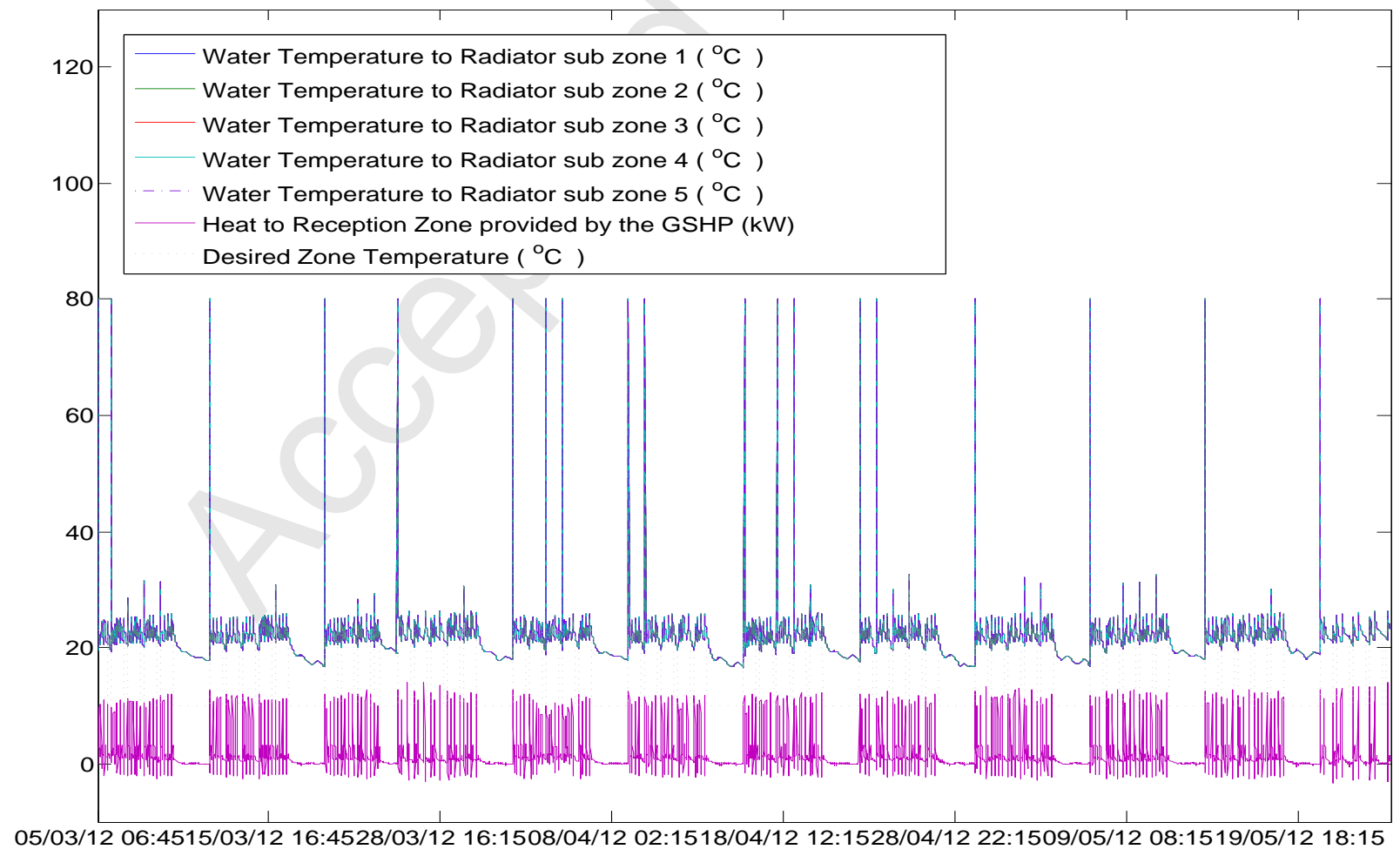

Figure 14: The energy for the Reception Zone when utilising the proposed MAS BMS Scenario 3. Figure shows the GSHP is the main heat provider to the zone. 


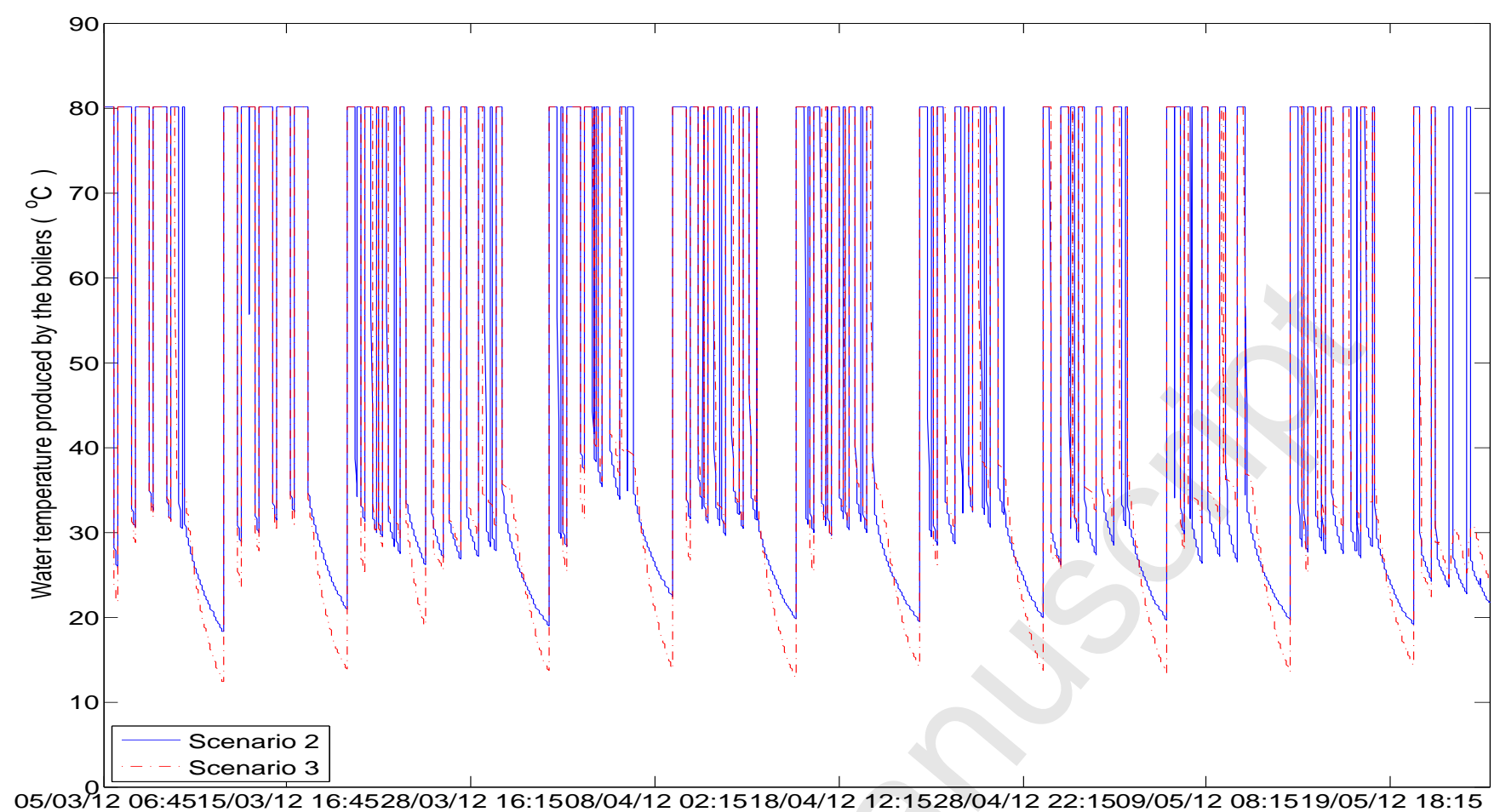

Figure 15: The hot water produced by the gas boilers for Scenarios 2 and 3; resulted in the small energy saving indicated in Table 2.

Source Agents can help maximise the advantage of incorporating the GSHP energy technology, which in turn helps in the reduction of energy costs and the lowering of $\mathrm{CO}_{2}$ gas emissions.

The implementation of the ARTMAP-MAS BMS is currently underway within the university, beginning with the implementation of the User Agents to the rooms in the building. The work then continues with the implementation of the Source Agents to the gas boilers and the GSHP; where issues in integrating the Source Agents with the existing control systems of the boilers and the GSHP are envisaged. Future work includes: investigating potential limitations of the integration and finding solutions to the identified limitations, as well as investigating the suitability of the proposed MAS to provide cost effective integration of multiple types of renewable electric generators to the building.

\section{Acknowledgement}

The authors would like express their gratitude to the UCLan Facilities Management in all their help in providing information with regards to the heat demand and resources of the Samuel Lindow Building. The work is joint funded by BAE Systems, UK.

[1] Zero Carbon Britain. [Online] http://www.zcb2030.org/

[2] A. Howe, "Dynamic demand could help balance electricity systems," Energy World, Energy Institute, London, Nov. 2009.

[3] H. Esen, M. Inalli, A. Sengur and M. Esen, "Modelling a Ground-Coupled Heat Pump System Using Adaptive Neuro-Fuzzy Inference Systems", International Journal of Refrigeration, vol. 31, no. 1, pp. 65-74, 2008
[4] H. Esen, M. Inalli, A. Sengur and M. Esen, "Artificial Neural Networks and Adaptive Neuro-Fuzzy Assessments for Ground-Coupled Heat Pump System", Energy and Buildings, vol. 40, no. 6, pp. 1074-1083, 2008.

[5] H. Esen and M. Inalli, "ANN and ANFIS models for performance evaluation of a vertical ground source heat pump system", Expert Systems with Applications, vol. 37, no. 12, pp. 8134-8147, 2010.

[6] M. Mohanraja, S. Jayaraj and C. Muraleedharan, "Applications of artificial neural networks for refrigeration, air-conditioning and heat pump systems - A review", Renewable and Sustainable Energy Reviews, vol. 16, no. 2, pp. 1340-1358, 2012.

[7] Energy Saving Trust, "Getting warmer: a field trial of heat pumps," 2010 [Online] http://itsacoastthing.com/pdf/EST_Getting_warmer a_field_trial_of_heat_pumps_report[1].pdf

[8] N. Bergman, "Why is Renewable Heat Undeperforming? A SocioTechnical Perspective," 2011 [Online] http://scholar.googleusercontent .com/scholar?q=cache:nY-EoZZqIysJ:scholar.google.com/+why+is+ renewable+heat+underperforming $\& \mathrm{hl}=\mathrm{en} \&$ as $\mathrm{sdt}=0,5$

[9] Energy Saving Trust, "Detailed analysis from the first phase of the Energy Saving Trust's heat pump field trial: Evidence to support the revision of the MCS Installer Standard," MIS 3005, no 3.1, 2012 [Online] http://www.decc.gov.uk/assets/decc/11/meeting-energydemand/microgeneration/5045-heat-pump-field-trials.pdf

[10] S. Caird, R. Roy and S. Potter, "Domestic heat pumps in the UK: user behaviour, satisfaction and performance," Energy Efficiency, vol. 5, no. 3, pp. 283-301, 2012.

[11] X. Liu, I. Chilvers, M. Mokhtar, A. Bedford, K. Stitt and J. Yazdani, "Microgrid Development for Properties", in The 2nd European Conference on Innovative Intelligent Grid Technologies (ISGT-EUROPE 2011), 2011.

[12] Veissmann, Vitocell 300-B DHW cylinder with two indirect coils 300 and 500 litre capacity, [Online] http://www.viessmann.co.uk/etc/ medialib/internet_uk/technical_updates.Par.73739.File.File.tmp/Vitocell300B Datasheet.pdf

[13] Veissmann, "Vitocal 300G Boiler and Heat Pump Data Sheet", VITOCAL 300/350 Heat pump: Brine/Water - 6.4 to $32.6 \mathrm{~kW}$, Water/Water - 8.4 to $43.0 \mathrm{~kW}$, [Online] http://www.viessmann.co.uk/ etc/medialib/internet_uk/attachments/datasheets_technical/heat_pumps. 
Par.95308.File.File.tmp/Vitocal300350Datasheet.pdf

[14] P. Davidsson and M. Boman, "Distributed Monitoring and Control of Office Buildings by Embedded Agents," Information Sciences, vol. 171, pp. 293-307, 2005

[15] B. Shen, G. Zhang, L. Zhang and M. Wang, "Multi-Agent System Design for Room Energy Saving", in 2010 5th IEEE Conference on Industrial Electronics and Applications, pp.840-844, 2010.

[16] B. Qiao, K. Liu, and C. G. Guy, "A multi-agent system for building control", In Proceedings of IEEE/WIC/ACM International Conference on Intelligent Agent Technology (IAT-6), Hong Kong, 2006.

[17] M. Mokhtar, X. Liu, "An ARTMAP-incorporated Multi-Agent System for Building Intelligent Heat Management", in The 3rd European Conference on Innovative Intelligent Grid Technologies (ISGT-EUROPE 2012), 2012.

[18] A. I. Dounis, D. E. Manolakis. "Design of a fuzzy system for living space thermal comfort regulation", Applied Energy 2001, vol. 69, pp. 119-144, 2001

[19] A.I. Dounis, C. Caraiscos, "Advanced control systems engineering for energy and comfort management in a building environment - A review". Renewable and Sustainable Energy Reviews, Vol. 13, Issues 6-7, pp. 12461261, 2009.

[20] M. Gouda, S. Danaher, C. Underwood, "Thermal comfort based fuzzy logic controller", Building Services Engineering Research and Technology 2001, vol. 22, no. 4, pp. 237-253, 2001.

[21] D. Kolokotsa, "Comparison of the performance of fuzzy controllers for the management of the indoor environment", Building and Environment, vol. 38, pp. 1439-1450, 2003.

[22] F. Calvino, M. L. Gennusca, G. Rizzo, G. Scaccianoce, "The control of indoor thermal comfort conditions: introducing a fuzzy adaptive controller", Energy and Buildings, vol. 36, pp. 97-102, 2004

[23] J. Liang and R. Du, "Thermal Comfort Control Based on Neural Network for HVAC Application”, Proceedings of the 2005 IEEE Conference on Control Applications, Toronto, Canada, August, 2005.

[24] F. Yamada, K. Yonezawa, S. Sugarawa, N. Nishimura, "Development of air-conditioning control algorithm for building energy-saving," In IEEE International Conference on Control Applications, 1999.

[25] M. Mokhtar, X. Liu, J. Howe, "Multi-Agent Gaussian Adaptive Resonance Theory Map for Building Energy Control and Thermal Comfort Management of UCLan's Westlakes Samuel Lindow Building", Submitted to Energy and Building, Elsevier, 2012.

[26] J. Williamson, "Gaussian ARTMAP: A neural network for fast incremental learning of noisy multidimensional maps," Neural Networks, vol. 9, no. 5, pp. 881-897, 1996.

[27] G. Carpenter, S. Grossberg, and J. Reynolds, "ARTMAP: Supervised realtime learning and classification of nonstationary data by a self-organizing neural network," Neural Network, vol. 4, pp. 565-588, 1991.

[28] G. Carpenter, S. Grossberg, N. Markuzon, J. Reynolds, and D. Rosen, "Fuzzy ARTMAP: A neural network architecture for incremental supervised learning of analog multidimensional maps," IEEE Trans. Neural Networks, vol. 3, no. 5, pp. 698-713, 1992.

[29] Matlab, "Thermal Model of a House," [Online] Available: http://www. mathworks.co.uk/products/simulink/demos.html?file=/products/demos /shipping/simulink/sldemo_househeat.html

[30] ASHRAE Handbook Fundamentals, 2005.

[31] Department of Energy \& Climate Change, "Renewable Heat Incentive (RHI) Scheme," [Online] Available: http://www.decc.gov.uk/en/content/cms/meeting_energy/renewable_ener /incentive/incentive.aspx 
Highlights

1. We created a UCLan Westlakes Samuel Lindow Building with GSHP heat simulation model.

2. We proposed an ARTMAP multi-agent intelligent heat management system.

3. ARTMAP provides better heat distribution in comparison to other systems.

4. The proposed technique has solved the underperforming issues of GSHP.

5. ARTMAP has caused lesser heat to be produced by the boilers. 